\title{
Analysis of Chinese College Students' English Learning Motivation and Countermeasures from the Perspective of General Education
}

\author{
Beini Peng \\ Hubei University of Chinese Medicine, Wuhan, 430065, China
}

Keywords: All-round-knowledge-based education. Learning motivation. Necessity. Teaching contents

\begin{abstract}
This article tends to highlight the necessity of Productive Bilingualism through the analysis of learning motivation of college students; All-round-knowledge-based education requires optimizing college English curriculum system and enriching teaching materials and methods so as to cultivate their critical thinking and innovative abilities. In this way, better and more efficient teaching effects can be achieved.
\end{abstract}

Language acts as both a communication tool and a cultural mirror. Classical researches on social mentality of language study pay much attention to learners' learning motivation or orientation. Garden and Lambert (1972) deem that learning motivation or orientation can be mainly divided into two types: 'tool type', i.e., language is used as a tool to achieve a certain communicative purpose, such as finding a satisfying job, entering a higher school, going abroad and parents' expectation etc., and 'integration type', i.e., learning and integrating with target-language culture. Different learning objectives directly affect learning strategies and effect.

Since the 1990s, some foreign scholars have proposed that we need consult theories of psychology more widely (such as Maslow's theory of need hierarchy and research results of management psychology in the aspect of job satisfaction status) to expand classical motivation mode of Garden (1985). Currently, different expansion modes mainly include new factors like 'learning situation', 'target significance' and 'self-efficacy' (Tremblay \& Garden, 1995) etc. At the same time, differences in learners' personal characteristics, such as age, gender and learning strategies, have drawn more and more attention from scholars.

Most empirical researches on learning motivation in China follow the direction of classical and expansion mode, explore promoting effect of motivation on academic performance and study relationship between motivation and other factors affecting learners' performance. Motivation that some researches with huge influence pay attention to lays particular stress on the behavioral level, i.e., 'effort level', but do not divide motivation into detailed types scientifically (Wu Yian, Liu Runqing and Jeffery, 1993; and Liu Runqing and Wu Yian, 2000). Some Chinese scholars suggest that 'certificate-type motivation' is main force driving Chinese college students' English study (Hua Huidang, 1998; and Shi Yongzhen, 2000).

With respect to learning motivation, the author tends to support the scholar Gao Yihong's opinion, i.e., 'productive bilingualism' phenomenon. This productive bilingualism phenomenon means mastery of mother tongue and target language and comprehension of mother tongue culture and target-language culture bring out the best in each other and interact with each other actively. Meanwhile, the author combines it with general education, which makes cognition, emotion and behavioral ability of English learners be improved obviously.

Undergraduate students in China have experienced college entrance examination with fierce competition, so they have laid a foundation in the aspect of English listening, reading and writing ability. However, many students dare not speak English aloud, let alone give lectures in English at public occasions. The reason for this is that they are affected by many factors, such as insufficient systematic listening training for a long time, limited vocabularies and introversion. Many English learners have neither explicit learning objectives nor full-bodied interest. Of course, all of these are related to teachers' teaching methods. However, students' learning motivation is a leading factor. They usually pay more attention to academic performance and lay stress on whether they can pass 
CET-4 and CET-6 examinations in order that they can find more satisfying jobs in future. Some other students aim at watching hot Britain and American plays more easily by learning English. In fact, the most essential significance of language study directs at meaningful communication. Learning English well can help students perfect their character, improve critical thinking skills and lay a foundation to be international talent, which is also the final direction of general education.

Currently, there are few research literatures on college English teaching from the perspective of general education. Since 1995, researches have mainly focused on these aspects including teaching concept, teaching goal, teaching methods, teaching evaluation system and college English teachers. However, related researches lack systematicness and maneuverability. H. H. Stern and Ullmann hold that foreign language teaching objectives can be summarized as four types, i.e., linguistic proficiency, knowledge, sentiment and values as well as skill transfer. In the West, especially at some American colleges, for instance, Massachusetts Institute of Technology, general education is carried out in English teaching, which provides a language tool for students to join global community sensitively and successfully and obtains good effect. In China, it was Mei Yiqi the former headmaster of Tsinghua University that proposed general education for the first time. In My Idea on University, he clearly proposes the objective to cultivate 'general' talent. Mei Yiqi's general education opinion mainly contains the following aspects. Firstly, life is greater than major and career is only a part of life. Secondly, general knowledge is preparation for common life and professional knowledge is preparing for special life. Thirdly, from the perspective of social demands, 'all-round people come first and experts come second'. Fourthly, if experts with a basis of general knowledge are asked to govern a country, the result will not 'benefit people' but 'disturb residents'. Doctor Li Manli a famous educationalist (Li Manli, 1999) divides general education into three types in the aspects of nature, purpose and content of general education: firstly, she expounds general education from the perspective of nature, deems that general education is 'non-professional and non-vocational education', whose meaning is the same as that of liberal education, and thinks that nature of general education is that freedom and humanistic tradition are inherited; secondly, she states general education from the perspective of educational purpose, thinks that general education directs at cultivating sound individuals and perfect citizens in free society and training talented people with broad insight, profound knowledge and experience, well-informed and refined spirit and graceful emotions and emphasizes that generation education is a kind of education that pays attention to harmonious development of people's life, morality and intellect; thirdly, she discusses general education from the perspective of its content, points out that general education should give 'accurate and common knowledge of all subjects' to students and deems that general education is a kind of education that is related to knowledge and skills in all fields of people's life and the scope that it involves is wide and comprehensive. The scholar Wu Dingmin thinks that it is essential to expand course functions of college English, pay attention to cultivating English ability and consciousness of cross-cultural communication and obtain multidisciplinary knowledge by English.

'General education' is neither vague education about general knowledge nor the education for all people in sense of universal education. It is used to refer to the situation that a part of overall education is identified. This part pays attention to people's life first and aims at making people be responsible human beings and citizens. 'Professional education' is a kind of education that aims at cultivating sills need by a certain career that a person will be engaged in future. They are two aspects of people's life and cannot and must not be separated from each other. As Chinese college students, they not only act as a whole and many individuals but also serve as national citizens following the same road and walking toward to a common future as well as a number of individuals moving ahead on different roads. This dual nature is just the basis on which general education and professional education combine with one another. At present, a number of Chinese college students lack both humanistic and scientific literacy. Meanwhile, many students become incapable of thinking and lack ability to solve practical problems and rethink about things. Then, how can we put the concept that general education and professional education combine with one another into practice in college English teaching? 
The author deems that it is essential to establish a favorable curriculum system related to college English. Classroom teaching is a subject of college education and cultural quality education can be realized partially by classroom teaching. After about 20 years' exploration in general education, the practice that has been basically formed is that courses for undergraduate students' four-year college study include three types, i.e., required course, restrictively optional course and freely optional course. Courses of general education usually contain elective courses like intersection elective course of arts and science and art-type elective course. Of course, all universities have both similarities and differences in specific subjects, forms in which courses are taken and requirements. For instance, introduction to background knowledge in the aspect of traditional Chinese and western medicine culture can be added at colleges of traditional Chinese medicine and sources of the Olympic spirit and practical methods can be explained at institutes of physical education. Besides, it is essential to make full use of the first 5 minutes of a lesson to cultivate students' inherent interest in English study actively and arouse their learning enthusiasm and initiative. All of thee propose higher requirements for English teachers at colleges.

Secondly, it is possible to develop discussion on topics that approach the era and students' life in classroom, for example, how can we inherit and develop traditional culture of China in the process in which modern science and technology are developed? Modern communication and information are developed gradually. As a result, many people are used to communicating and exchanging with others by methods like WeChat, microblog and E-mail. However, they have fewer and fewer chances to write Chinese characters and usually encounter the phenomenon of character amnesia. In consequence, wrongly written characters appear endlessly. Moreover, a number of students are addicted to pop music, for instance, rock, but do not show any interest in essence of Chinese traditional culture, such as Kunqu opera and Beijing Opera. At the same time, some old craftsmanship also faces with the crisis that they may be lost. Under the condition of market-oriented economy, how can we inherit and develop Lei Feng's spirit better, make mutual help become a habit and reach a social consensus? In English discussion, it is easy to make students realize brilliance is added to present splendor undoubtedly. However, humanistic care that timely help should be provided is also the quality that young people must have in this era. It is essential to enhance interaction and communication with students, learn their ideological trend, pressure and confuse, dredge unhealthy emotions actively, promote students' sound development in both body and mind and enable them to devote themselves to study and life better.

In addition, strengthen cultivation of extracurricular practical ability in the aspect of English, encourage students to develop a habit of reading classical famous literary works in English, arouse their interesting in English study in many forms like participating in English dramatic performance, music drama, debate competition in English and speech contest etc., improve their oral ability and develop their thinking and debating talent. Meanwhile, it is important to enrich listening materials. In detail, teaching materials should not only be limited to textbooks for listening and speaking. Instead, some classical original movies, Britain and American plans and English documentaries may be involved. Meanwhile, students should not be satisfied with simple listening but carry specific learning tasks to learn authentic English use and vocabularies in specific context in order to perfect their English writing and translating level.

\section{Acknowledgments}

This thesis is a school-level educational and teaching project in 2013: Reform of College English Teaching Mode at Colleges of Traditional Chinese Medicine from the Perspective of General education and a research project related to humanistic and social science at Education Department of Hubei Province: A Research on Comparison between Shakespeare's Comedy The Two Gentlemen of Verona and Kunqu Opera Romance of the Western Chamber from the Perspective of Interpersonal Function (project No.: 13g074). 


\section{References}

[1] Garden, R.C. Social Psychology and Second Language Learning: The Role of attitude and motivation, London: Edward Arnold, 1985.

[2] Lambert, W.E. Language, Psychology, and Culture, Stanford, California: Stanford University Press, 1972.

[3] Tremblay,P. F.\& Garden, R.C. Expanding the motivation construct in language learning. [J] Modern Language Journal, 79, 505-520 1995.

[4] Gan Yang. Two Central Links in General education at Colleges, Reading, 2006(4):3-12.

[5] Hua Huifang. Discussion on Researches on English Learning Motivation and Strategies, Foreign Language World, 1998(3).

[6] Shi Yongzhen. An Investigation Report on College Students' English Learning Motivation, Foreign Language Teaching Abroad, 2000(4).

[7] Li Manli. General education: A College Education View, Beijing: Tsinghua University Press, 1999: 231-232.

[8] Wen Qiufang. Change Law and Features of English Learners' Motivations, Opinions and Strategies, Foreign Language Teaching and Research, 2001(2).

[9] Wu Yian, Liu Runqing and Jefferey, P. An Investigation Report on Quality of Undergraduate Students Majoring in English in China, Foreign Language Teaching and Research, 1993(1).

[10] Zhang Donghai. General education: Misunderstanding about Concepts and Dilemma of Practice-Understanding Connotation of General education from the Perspective of Holistic Education, Fudan Education Forum, 2008(04). 